\title{
Specificity of the extender used for freezing ram sperm depends of the spermatozoa source (ejaculate, electroejaculate or epididymis)
}

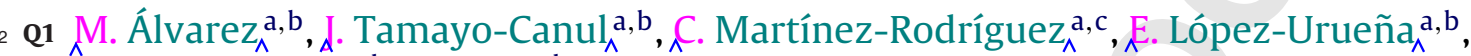

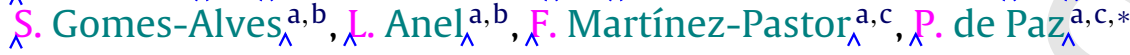 \\ a ITRA-ULE, INDEGSAL, University of León, 24071 León, Spain \\ b Animal Reproduction and Obstetrics, University of León, 24071 León, Spain \\ c Molecular Biology, University of León, 24071 León, Spain
}

\section{A R T I C L E I N F O}

\section{Article history:}

Received 9 December 2011

Received in revised form 3 May 2012

Accepted 9 May 2012

Available online $\mathrm{xxx}$

\section{Keywords:}

Spermatozoa

Ejaculate

Electroejaculate

Epididymis

Ram

Cryopreservation

Egg yolk

Glycerol

\begin{abstract}
A B S T R A C T
The objective of this study was to identify possible specificity in the extender formulation for the cryopreservation of ram spermatozoa recovered from three origins (ejaculate, electroejaculate or epididymis), by evaluating post-thawing sperm quality and fertility. Ejaculated, electroejaculated or epididymal spermatozoa samples obtained from identical rams (8) were cryopreserved in four different extenders (TES-Tris-fructose with one of two egg yolk concentrations: $10 \%$ Y10 and 20\% Y20, and with one of two glycerol rates: $4 \%$ G4 and $8 \%$ G8). Samples were analyzed before and after cryopreservation by CASA (motility) and flow cytometry (viability with SYBR-14/PI and acrosomal status with PNA/PI). Spermatozoa obtained by electroejaculation were of poorer quality after freezing/thawing, demonstrating that protocols for these samples need to be optimized. Egg yolk at $20 \%$ was more appropriate for freezing sperm from any of the sources. In general, $4 \%$ glycerol improved the quality of post-thawing samples recovered from ejaculate and electroejaculate, while $8 \%$ glycerol was more appropriate for samples recovered from the epididymis. Based on these results, an analysis of fertility was conducted. Fertility rates were similar between ewe groups inseminated with post-thawed sperm obtained from two sources: ejaculate (cryopreserved in Y20 + G4), and cauda epididymis (Y20+G8), and this rate was less in the electroejaculated sample (Y20+G4).
\end{abstract}

(C) 2012 Published by Elsevier B.V.

Q2 * Corresponding author at: ITRA-ULE, INDEGSAL, University of León, 24071 León, Spain. Tel.: +34 9872915679.

E-mail address: ppazc@unileon.es (P. de Paz).

genetic variability due to selection programs (Ehling et al., 2006; Nel-Themaat et al., 2006). Unfortunately, the success reached in the cryopreservation of bull sperm has not been transferred to more commonly raised farm animal species including the ram (Salamon and Maxwell, 2000). Thus, artificial insemination programs with cryopreserved ram spermatozoa do not satisfy the demand of the sheep industry (Gillan et al., 1999), because acceptable results for fertility have only been obtained with laparoscopic intrauterine insemination, a complex technique unsuitable for field conditions (Anel et al., 2006).

Sperm undergo considerable cellular, biochemical and osmotic changes during epididymal maturation and after the addition of seminal fluids (James et al., 1999; 
Martinez-Pastor et al., 2006; Yeung et al., 2006; TamayoCanul et al., 2011b). These changes include a significant variation in the plasma membrane components of ram spermatozoa (Hammerstedt and Parks, 1987) that subsequently affect the cryobiological properties of semen. Understanding the effects of cryoprotective agents on the cellular system during cryopreservation is a prerequisite for developing improved protocols for freezing (Curry and Watson, 1994). Although several studies have been conducted on osmotic tolerance, cold shock sensitivity and hydraulic conductivity of ram ejaculated sperm during freezing (Curry and Watson, 1994; Anel et al., 2003), these properties have not been fully investigated for electroejaculated or epididymal ram sperm.

Appropriate retrieval and optimal cryopreservation of epididymal spermatozoa following accidental death in ram and other endangered species would also greatly help to preserve biodiversity (Kaabi et al., 2003; Hishinuma et al., 2003; Martinez-Pastor et al., 2009; Fernández-Santos et al., 2006). For this reason, there is a need to investigate and compare the fundamental cryobiological characteristics of ejaculates and electroejaculated and epididymal sperm (Holt, 2000).

Egg yolk and glycerol are indispensable compounds for practically all media used for sperm conservation in liquid or frozen states in domestic animals. Egg yolk has a beneficial effect on sperm cryopreservation and it is speculated that its components associate with sperm membranes and provide protection against cold shock (Moussa et al., 2002; Manjunath et al., 2002; Amirat et al., 2004; Hu et al., 2010). Glycerol contributes to sperm integrity conservation in cryopreservation procedures. However, the optimal concentration of glycerol is yet to be defined because comparative studies in different species have generally been conducted using extender with many varying parameters (sugar, membrane stabilizer, glycerol concentration, etc.), thus making it difficult to determine the most adequate glycerol concentration. Some authors have reported concentration ranges from 4\% to 10\% (Martinez-Pastor et al., 2006; Anel et al., 2003; Forouzanfar et al., 2010; de Paz et al., 2012; Alvarez-Rodríguez et al., 2011), but results seem to depend on other components or protocols followed rather than on glycerol concentration.

In the present study, we evaluated the effect of four types of extender obtained from the combination of two egg yolk concentrations (10\% and $20 \%$ ) with two glycerol concentrations ( $4 \%$ and $8 \%$ ) on freezing semen from three different sources (ejaculated, electroejaculated and epididymis) obtained from identical rams. A fertility trial was conducted using semen samples from the three sources.

\section{Materials and methods}

\subsection{Reagents}

All the products were obtained from Sigma (Madrid, Spain), except the SYBR-14 (LIVE/DEAD Sperm Viability Kit) and YO-PRO-1 fluorescence probes, which were acquired from Invitrogen (Barcelona, Spain).

\subsection{Animals}

Adult 5- to 7-year-old Assaf rams were used (eight for in vitro evaluation and three for the fertility test) belonged to the Spanish Assaf Breeders Association (ASSAFE). The rams of proven fertility were involved in a semen collection routine of three times per week during the breeding season.

\subsection{Semen collection}

Semen samples were obtained during the breeding season from three sources (ejaculate, electroejaculate or epididymis), taking samples from the same males sequentially (eight males for in vitro study and three males for the fertility trial). In a first phase, sperm were obtained from the ejaculate (see Section 2.3.1); then, after a rest period of 7 days, semen was obtained by electroejaculation (see Section 2.3.2) and after 7 days of rest, epididymal spermatozoa (see Section 2.3.3) were obtained.

\subsubsection{Ejaculate recovery}

Ejaculates were collected by artificial vagina at $40^{\circ} \mathrm{C}$ (Minitüb, Tiefenbach, Germany), and the tubes were maintained at $35^{\circ} \mathrm{C}$ during the initial evaluation of semen quality. The volume was estimated by using the graduation marks of the collection tube. Mass motility was assessed by microscopy (warming stage at $38^{\circ} \mathrm{C}, 40 \times$; score: $0-5$; Labophot 2, Nikon, Tokyo, Japan), and the sperm concentration was assessed by the photocolorimetric method at $540 \mathrm{~nm}$ (Spectronic 20, Baush \& Lomb, Madrid, Spain), on a specific calibrated scale. Only ejaculates of good quality were used and frozen (volume: $\geq 0.5 \mathrm{ml}$; mass motility: $\geq 4$; sperm concentration: $>3000 \times 10^{6} \mathrm{ml}^{-1}$ ).

\subsubsection{Electroejaculation procedure}

Prior to electroejaculation, the rams were restrained and anesthetized with intravenous injection of xylacine $0.1 \mathrm{mg} / \mathrm{kg}$ and ketamine $2.5 \mathrm{mg} / \mathrm{kg}$ (Rompum ${ }^{\circledR} 2 \%$, Bayer and Imalgene $1000^{\circledR}$, Merial). The rectum was cleaned of feces and the prepucial area shaved and washed with physiological saline serum. Electroejaculation was conducted using a 3 electrode probe $(250 \mathrm{~mm} \times 30 \mathrm{~mm})$ connected to an electroejaculator which allowed voltage and amperage control. Ejaculation occurred at average values of $4 \mathrm{~V}$ and $90 \mathrm{~mA}$ (average time to ejaculation: $3 \mathrm{~min}$ ).

\subsubsection{Post-mortem sperm recovery}

The testicles and epididymis were transported at room temperature $\left(22^{\circ} \mathrm{C}\right)$ and semen collection was conducted in the first $2 \mathrm{~h}$ after the slaughter of the ram. The epididymis-testicle complexes were dissected and cauda epididymis was isolated. Sperm was obtained by deep slicing of the cauda epididymis tissue with a scalpel; the fluid was collected and its volume was estimated. To avoid blood contamination, superficial blood vessels were previously cut and their contents were removed by wiping. 


\subsection{Cryopreservation procedure}

\subsubsection{Preparation of the extenders}

The extenders were based on a TES-Tris-fructose adjusted to $320 \mathrm{mOsm} / \mathrm{kg}$ and pH 7.2 (TTF, Anel et al., 2003) and complemented with one of two egg yolk concentrations (Y10: 10\% and Y20: 20\%) and one of two glycerol rates (G4: 4\% and G8: 8\%). To prevent variations in the egg yolk, it was obtained from fresh hen eggs in aseptic conditions, and all the yolks were pooled.

\subsubsection{Cryopreservation protocol}

The samples were diluted 1:1 in the corresponding extender. This dilution was performed at ambient temperature for different samples. The tubes with diluted sperm samples were then put in a glass containing $50 \mathrm{ml}$ of water at ambient temperature and transferred to a cold room at $5{ }^{\circ} \mathrm{C}$ for an average of $2 \mathrm{~h}$, until the samples reached a temperature of $5^{\circ} \mathrm{C}$, so the temperature decreased smoothly. The sample was then further diluted with the same extender to $100 \times 10^{6} \mathrm{sperm} / \mathrm{ml}$, packed in $0.25 \mathrm{ml}$ French straws and equilibrated for $1 \mathrm{~h}$ at $5^{\circ} \mathrm{C}$. Sperm were subsequently frozen at $-100{ }^{\circ} \mathrm{C}$ using a programmable biofreezer (Kryo 560-16 ${ }^{\circledR}{ }^{\text {Planer }}{ }^{\mathrm{TM}}{ }^{\mathrm{N}}$, Planer plc., Sunbury-On-Thames, UK) using a rate of $-20^{\circ} \mathrm{C} / \mathrm{min}$. The straws were kept in liquid nitrogen containers. Thawing was performed in a water bath at $65^{\circ} \mathrm{C}$ for $6 \mathrm{~s}$. Sperm quality parameters were evaluated immediately after thawing.

\subsection{Spermatozoa evaluation}

\subsubsection{Motility parameters}

Motility was assessed using a computer-assisted sperm analysis system (CASA) (ISAS ${ }^{\circledR}$ v. 1.1; Proiser, Valencia, Spain). Samples were diluted $\left(10-20 \times 10^{6}\right.$ cells $\left./ \mathrm{ml}\right)$ in the same TTF medium with $320 \mathrm{mOsm} / \mathrm{kg}$, and warmed on a $37^{\circ} \mathrm{C}$ plate for $5 \mathrm{~min}$. Then, a 5 - $\mu \mathrm{l}$ drop was placed in a Makler ${ }^{\circledR}$ counting cell chamber (10 $\mu$ m depth; Sefi Medical Instruments, Haifa, Israel). The sample was examined at $10 \times$ (negative phase contrast) under a microscope (Eclipse E400 ${ }^{\circledR}$, Nikon) with a warmed stage $\left(38^{\circ} \mathrm{C}\right)$. The standard parameter settings were set at 25 frames/s, $20-90 \mu \mathrm{m}^{2}$ for head area and VCL $>10 \mu \mathrm{m} / \mathrm{s}$ to classify a spermatozoon as motile (Tamayo-Canul et al., 2011a). At least five sequences or 200 spermatozoa were saved and analyzed afterwards. Reported kinetic parameters were curvilinear velocity (VCL, $\mu \mathrm{m} / \mathrm{s}$ ) and linearity (LIN, \%) according to bivariate model used by Cancel et al. (2000). Total motility (TM) was defined as the percentage of spermatozoa with $\mathrm{VCL}>10 \mu \mathrm{m} / \mathrm{s}$, and progressive motility (PM) was defined as the percentage of spermatozoa with $\mathrm{VCL}>25 \mu \mathrm{m} / \mathrm{s}$ and STR $>80 \%$ (straightness, also provided by the system).

\subsubsection{Sperm viability and acrosome status}

Acrosomal status was assessed using florescence probes (PNA/PI) and flow cytometry, according to methods described by (Martinez-Pastor et al., 2009). Briefly, samples were diluted in PBS at $5 \times 10^{6}$ spermatozoa $/ \mathrm{ml}$, and incubated for $15 \mathrm{~min}$ with $24 \mu \mathrm{M}$ of propidium iodide (PI) and $1 \mu \mathrm{g} / \mathrm{ml}$ of PNA-FITC (peanut agglutinin). PI stains membrane-damaged spermatozoa red, whereas PNA-FITC stains the acrosome green if it is damaged or reacted. Thus, four different subpopulations were obtained: red (non-viable sperm, intact acrosome), green (viable sperm, damaged acrosome) red and green (non-viable sperm, damaged acrosome) or non-stained (viable sperm, intact acrosome). The percentage of spermatozoa with damaged acrosomes (dACR) was calculated as the sum of viable and non-viable PNA + spermatozoa.

The double stain SYBR-14/PI (LIVE/DEAD Sperm Viability $\mathrm{Kit}^{\circledR}$ : Invitrogen, Barcelona, Spain) was used to evaluate sperm viability. Sperm samples were diluted with PBS down to $5 \times 10^{6}$ spermatozoa $/ \mathrm{ml}$, and incubated with $24 \mu \mathrm{M}$ PI and $100 \mathrm{nM} \mathrm{SYBR}-14$. The tubes were kept at $37^{\circ} \mathrm{C}$ for $20 \mathrm{~min}$ in the dark. Three populations were detected corresponding to live spermatozoa VIAB (green), moribund spermatozoa (red + green) and dead spermatozoa (red).

Evaluation was performed using a FACScalibur ${ }^{\circledR}$ flow cytometer (Becton Dicknson System, San Jose, CA, USA) equipped with standard optics and an argon-ion laser, tuned at $488 \mathrm{~nm}$, and running at $200 \mathrm{mV}$. Calibration was performed periodically using standard beads (Calibrites ${ }^{\circledR}$ : Becton Dickson). Data corresponding to the red (FL-3 photodetector) and green (FL-1 photodetector) fluorescence of 10,000 spermatozoa were recorded.

\subsection{Fertility trials}

A fertility trial was conducted using samples from three males obtained from the three sperm sources. The semen was frozen with the method that that provided the most desirable results in the in vitro study was TTF-Y20-G4 for ejaculates and electroejaculates and TTF-Y20-G8 for epididymal sperm. Adult Assaf ewes (356 females from 11 commercial farms) were subjected to treatment for oestrous induction and synchronization using intravaginal sponges with $20 \mathrm{mg}$ fluorogestone acetate (Chronogest ${ }^{\circledR}$, MSD) over 14 days. The sponges were removed and $500 \mathrm{IU}$ of eCG injected (Folligon ${ }^{\circledR}$, MSD). Laparoscopic inseminations were performed between 62 and $64 \mathrm{~h}$ after the removal of the sponges. The animals, having fasted for the previous $24 \mathrm{~h}$, were tied to a special cradle (IMV), placed on an inclined plane $\left(45^{\circ}\right)$ and the area in front of the teat was shaved and cleaned. Local anesthesia (mepivacaine HCL 2\%, Braun ${ }^{\mathrm{TM}}$ ) was applied to the puncture points. Then two portals (for vision and manipulation/injection) were inserted by performing a pneumoperitoneum $\left(\mathrm{CO}_{2}\right)$. The semen, placed in a special applicator (Transcap ${ }^{\circledR}$, IMV), was injected under visual inspection into each uterine horn $\left(0.12 \mathrm{ml}, 12.5 \times 10^{6} \mathrm{spz}\right)$. Fertility was evaluated in lambing ewes according to the births registered at $137_{-}-154$ days post-insemination.

\subsection{Statistical analysis}

Statistical analyses were conducted using the R statistical package version 2.13.0 (http://www.r-project.org). Arcsin transformation of the percentage data was employed to normalize the data before analysis. Normalized data were fitted to linear mixed-effect models by maximizing the loglikelihood (ML method) (R Development Core Team, 2010). Male was always included as random effect. Extender and 
M. Álvarez et al. / Animal Reproduction Science $x x x$ (2012) $x x x-x x x$

Table 1

Effect of ram semen source (ejaculate, electroejaculate or cauda epididymis) on quality in pre-freezing samples (mean \pm SEM).

\begin{tabular}{|c|c|c|c|c|c|c|}
\hline & TM (\%) & PM (\%) & $\mathrm{VCL}(\mu \mathrm{m} / \mathrm{s})$ & LIN (\%) & $\mathrm{dACR}(\%)$ & VIAB (\%) \\
\hline Ejaculate & $77.5 \pm 12.7$ & $59.0 \pm 13.5^{a}$ & $113.8 \pm 16.4^{\mathrm{a}}$ & $73.2 \pm 9.7^{a}$ & $11.4 \pm 5.7^{a}$ & $62.0 \pm 16.9^{a}$ \\
\hline Electroejaculate & $74.3 \pm 15.8$ & $46.6 \pm 15.8^{\mathrm{b}}$ & $110.8 \pm 30.6^{\mathrm{a}}$ & $65.6 \pm 10.6^{\mathrm{b}}$ & $16.0 \pm 10.8^{a}$ & $64.6 \pm 18.2^{\mathrm{a}}$ \\
\hline Cauda epididymis & $79.9 \pm 11.8$ & $57.6 \pm 11.0^{\mathrm{a}}$ & $128.4 \pm 21.8^{\mathrm{b}}$ & $68.9 \pm 8.8^{\mathrm{ab}}$ & $3.1 \pm 3.4^{\mathrm{b}}$ & $71.9 \pm 16.8^{\mathrm{b}}$ \\
\hline
\end{tabular}

TM, total motility; PM, progressive motility; VCL, curvilinear velocity; KIN, linearity; dACR, damaged acrosomes; and VIAB, viable spermatozoa.

(a,b) Different superscripts within columns indicate differences among sources $(P<0.05)$.

Table 2

Effect of ram semen source (ejaculate, electroejaculate or cauda epididymis) on quality in frozen-thawed samples (mean \pm SEM).

\begin{tabular}{llllll}
\hline & TM $(\%)$ & PM $(\%)$ & VCL $(\mu \mathrm{m} / \mathrm{s})$ & LIN $(\%)$ & VIAB $(\%)$ \\
\hline Ejaculate & $59.1 \pm 14.4^{\mathrm{a}}$ & $38.7 \pm 9.0^{\mathrm{a}}$ & $118.1 \pm 14.7^{\mathrm{ab}}$ & $68.4 \pm 5.4$ & $33.5 \pm 15.0^{\mathrm{a}}$ \\
Electroejaculate & $48.7 \pm 20.9^{\mathrm{b}}$ & $27.6 \pm 10.8^{\mathrm{b}}$ & $113.4 \pm 18.4^{\mathrm{a}}$ & $65.3 \pm 10.9$ & $29.3 \pm 12.9^{\mathrm{a}}$ \\
Cauda Epididymis & $62.0 \pm 16.2^{\mathrm{a}}$ & $41.5 \pm 11.5^{\mathrm{a}}$ & $126.3 \pm 16.8^{\mathrm{b}}$ & $68.5 \pm 8.2$ & $25.5 \pm 12.9^{\mathrm{a}}$ \\
\hline
\end{tabular}

TM, total motility; PM, progressive motility; VCL, curvilinear velocity; LIN, linearity; dACR, damaged acrosomes; and VIAB, viable spermatozoa.

$\hat{\lambda}$ a,b) Different superscripts within columns indicate differences among sources $(P<0.05)$.

sperm source were the fixed effects. Results are given as mean \pm SEM.

\section{Results}

\subsection{Effect of the semen source on pre-freezing and post-thawing quality}

The source of the spermatozoa influenced both prefreezing and post-thawing quality. The results of the pre-freezing analysis (samples extended and equilibrated at $5^{\circ} \mathrm{C}$ ) are shown in Table 1 . The method used for collecting the sample had no significant effect on the pre-freezing total motility, but affected $(P<0.05)$ the progressive motility and kinematic parameters. Electroejaculated samples had lesser values for progressive motility, whereas epididymal samples had the greatest values for VCL and viability, and the lowest proportion of damaged acrosomes.

The results of post-thawing quality are displayed in Table 2. There were several changes in motility, with electroejaculated samples having the least desirable kinematic parameters, being significant $(P<0.05)$ for total and progressive motility, and VCL. Ejaculated and epididymal samples did not differ significantly for CASA parameters. In general, there was an increase in damaged acrosomes and a severe decrease in the proportion of viable spermatozoa, in comparison with pre-freezing values. Epididymal samples again had the least desirable values for the proportion of damaged acrosomes, and the most desirable values for viable spermatozoa.

\subsection{Effect of egg yolk and glycerol concentration within each source}

The effect of egg yolk and glycerol on sperm quality and the interactions, both at pre-freezing and post-thawing, are shown in Figs. 1-4. In pre-freezing ejaculated samples, the total and progressive motility, curvilinear velocity and damaged acrosomes were affected by the egg yolk concentration $(P<0.05)$. In pre-freezing electroejaculated samples, only the damaged acrosomes were affected $(P<0.05)$ by the egg yolk. The curvilinear velocity and viability of semen from epididymal samples were affected by egg yolk $(P<0.05)$. The glycerol concentration had a marked effect $(P<0.05)$ on the progressive motility of prefreezing electroejaculated samples. Linearity was affected by glycerol $(P<0.05)$ in the three sperm sources and the viability was only affected $(P<0.05)$ in ejaculated samples.

After thawing, the ejaculated samples were affected by egg yolk concentration in lineality, damaged acrosomes (greatest concentration, less damage) and viability (greatest concentration, greater viability). Egg yolk concentration affected to total and progressive motility (highest concentration, greater motility), damaged acrosomes and viability (a greater concentration, greater viability) in the electroejaculated samples. The total and progressive motility of epididymal samples was also affected by egg yolk concentration in the same way.

Glycerol affected total motility post-thawing in epididymal samples $(P>0.05)$. The linearity was negatively affected $(P<0.05)$ by glycerol concentration in the three sources evaluated: ejaculate, electroejaculate and epididymis. Glycerol concentration increased $(P<0.05)$ the damage acrosomes in ejaculateand electroejaculated samples, and only the viability in ejaculated samples.

\subsection{Fertility trials for the three sources of semen}

There were no significant differences in the fertility obtained from the three sperm sources (Table 3 ). However, the electroejaculated samples proved for a lesser fertility ( $44.4 \%$ compared to ejaculated $(53.8 \%, P=0.062)$ and epididymal $(55.8 \%, P=0.082)$ samples.

\section{Table 3}

Fertility results (lambed/inseminated). A Chi squared test did not show significant differences between and sources (ejaculate compared to electroejaculate: $P=0.062$; epididymis compared to electroejaculate: $P=0.082$; and ejaculate compared to epididymis: $P=0.246$ ).

\begin{tabular}{llll}
\hline Source & Lambed ewes & Inseminations & Fertility (\%) \\
\hline Ejaculated & 63 & 117 & 53.8 \\
Electroejaculate & 56 & 126 & 44.4 \\
Cauda e્રpididymis & 63 & 113 & 55.8 \\
\hline
\end{tabular}



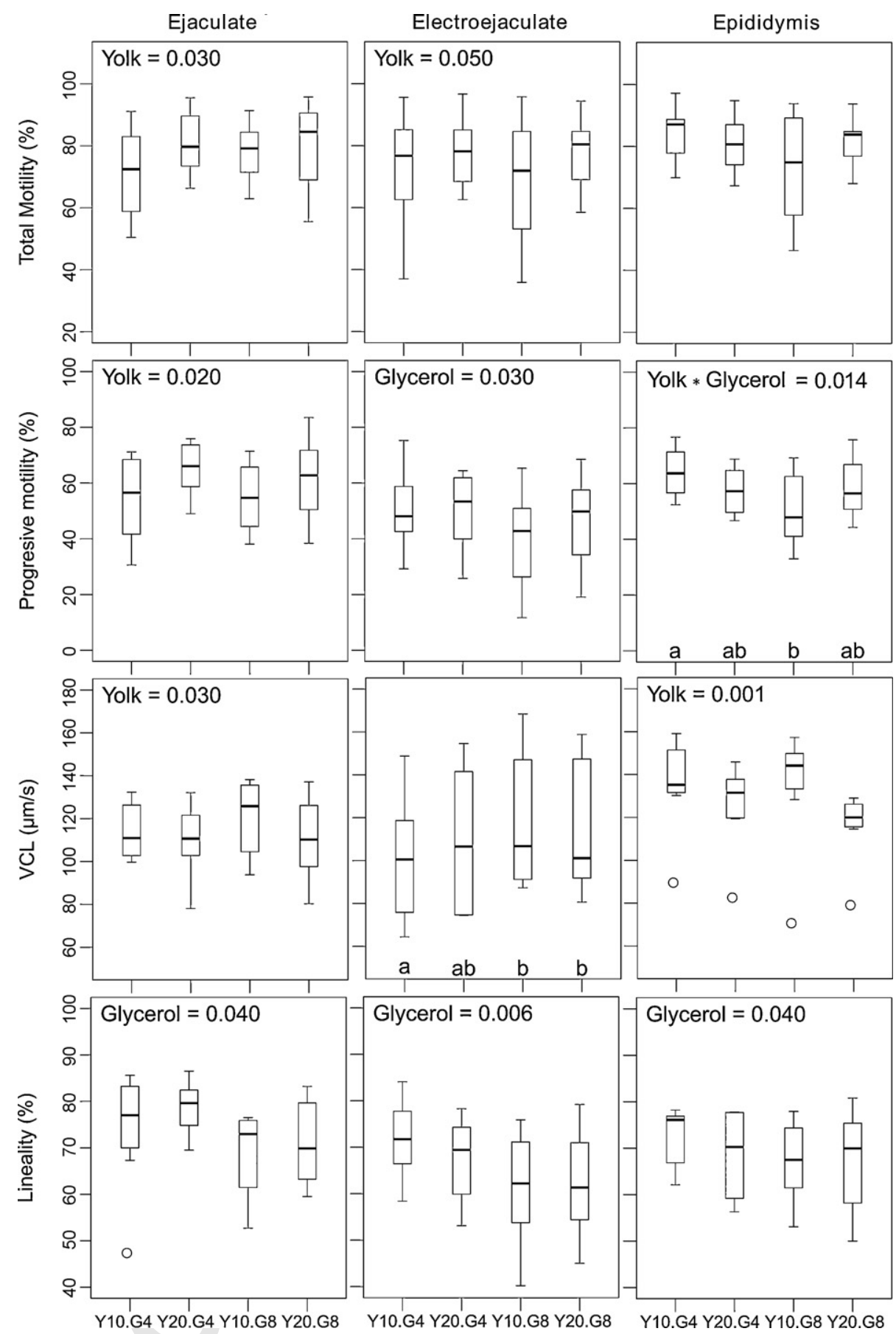

Fig. 1. Pre-freezing motility and kinetic parameters (CASA). The boxplot shows the parameters of semen obtained from three sources (ejaculate, electroejaculate or cauda epididymis) evaluated in four extenders (two concentrations of egg yolk (Y10: 10\%, Y20: 20\%) and two concentration of glycerol (G4: 4\%, G8: 8\%). Insets show whether the main effects (yolk or glycerol) or interactions (yolk $\times$ glycerol) were significant. Whenever a significant interaction was detected, a pairwise comparison was conducted of the four extenders (different letters indicate differences, $P<0.05$ ). The median is indicated by a horizontal line.

\section{Discussion}

This study directly compares the pre-freezing and post-thawing quality of sperm samples obtained from three sources from the same rams. Other studies have compared epididymal samples with either ejaculated or electroejaculated in other species. For example, Monteiro et al. (2011) observed that the viability and fertility of stallion cauda epididymal sperm are similar to those of ejaculated sperm, and Rath and Niemann (1997) concluded 

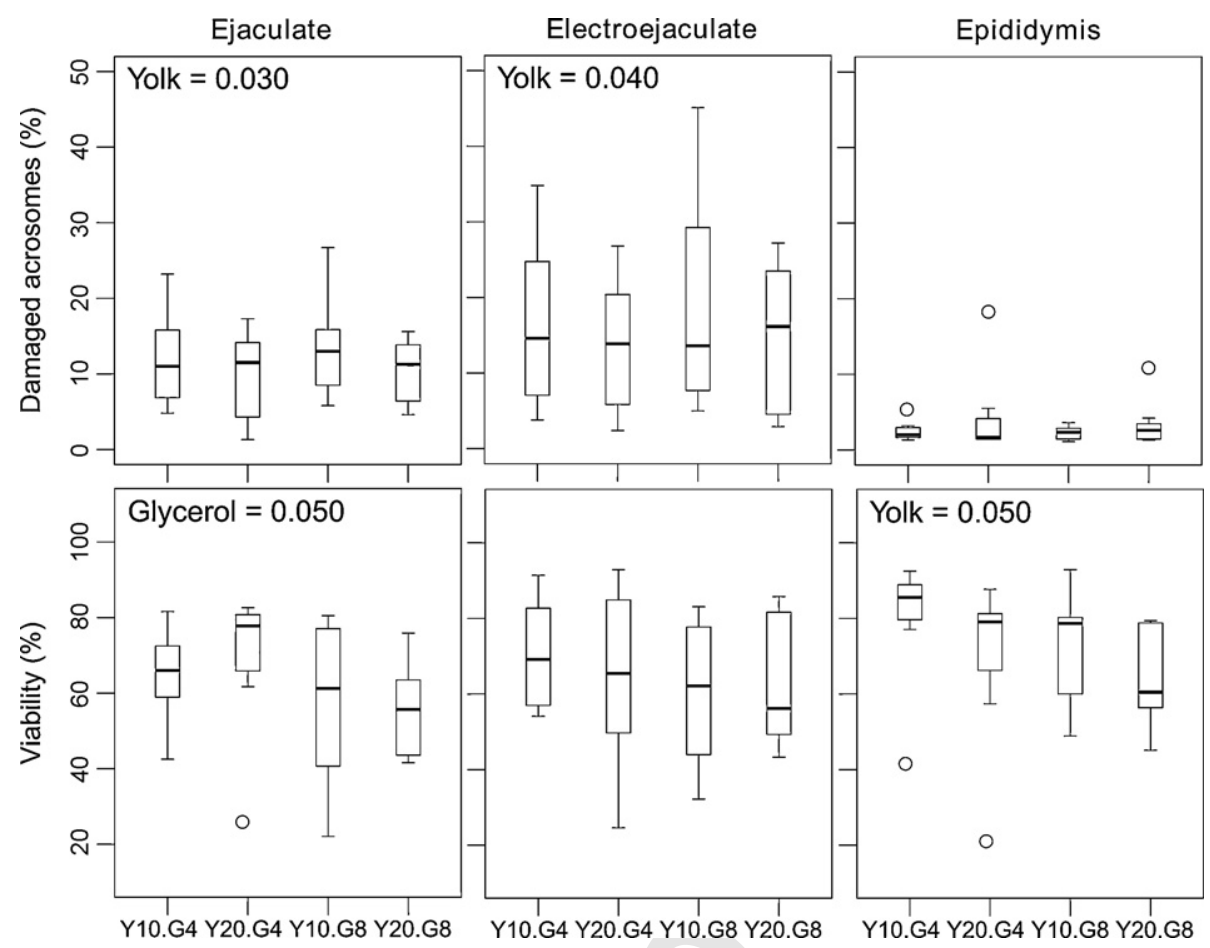

Fig. 2. Pre-freezing viability parameters (flow cytometry). The boxplot shows the parameters of semen obtained from three sources (ejaculate, electroejaculate or cauda epididymis) evaluated in four extenders (two concentrations of egg yolk (Y10: 10\%, Y20: 20\%) and two concentration of glycerol (G4: 4\%, G8: 8\%). Insets show whether the main effects (yolk or glycerol) or interactions (yolk $\times$ glycerol) were significant. Whenever a significant interaction was detected, a pairwise comparison was conducted of the four extenders (different letters indicate differences, $P<0.05$ ). The median is indicated by a horizontal line.

that boar epididymal spermatozoa can easily be frozen in small containers with greater resultant motility and fertilization rates than with ejaculated semen.

The post-mortem sperm recovery is a useful method for recovering germoplasm from dead animals that would otherwise be lost, especially for the creation germoplasm banks and to preserve endangered breeds, contributing to the preservation of biodiversity (Kaabi et al., 2003). The post-thawing results obtained by Fernández-Santos et al. (2006) from the red deer samples recovered from the epididymis indicated greater motility $(62.0 \pm 16.2 \%)$ than those reported in other studies for red deer (MartinezPastor et al., 2006), bulls (Martins et al., 2009) and rams (García-Álvarez et al., 2009). In the present study, the pre-freezing and post-thawing results showed that epididymal spermatozoa yielded motility values equal to or greater than ejaculated and electroejaculated samples, respectively. In fact, electroejaculated samples had lesser motility and viability post-thawing. These results contrast with those by Marco-Jiménez et al. (2005), who evaluated the effect of collection methods (ejaculation and electroejaculation) in the cryopreservation of Guirra rams spermatozoa. These authors found no differences in total motility and linearity. These results could be due to differences in the cryopreservation methods, which may have equalized the differences among sources. García-Álvarez et al. (2009) found considerable differences in total motility, after cryopreservation, in ram samples recovered from the epididymis and electroejaculated samples $(57.5 \pm 4.8 \%$ and $36.7 \pm 7.6 \%$, respectively). Subsequent studies have shown that electroejaculated samples had lesser resistance than did epididymal spermatozoa when submitted to cryobiologically stressful conditions such as chilling, osmotic stress, and addition and removal of the cryoprotective agent (Varisli et al., 2009). This could also explain fertility results in the present study, which were less than fertility in cryopreserved electroejaculated semen. These results indicate that cryopreservation protocols should be optimized for electroejaculated semen in rams, to obtain fertility similar to that observed with semen from the two other sources.

There were differences regarding the suitability of extenders for cryopreserving samples recovered from these three sources. Other researchers have made similar reports on other species. For example, Martinez-Pastor et al. (2006) described that epidydimal spermatozoa from red deer were cryopreserved with more desirable outcomes using $8 \%$ glycerol, whereas $4 \%$ was more adequate for electroejaculated samples. Nevertheless, similar to results in the present study, there were small differences between glycerol concentrations, especially for epididymal samples. In fact, these authors highlighted that epididymal spermatozoa could be resilient to different glycerol concentrations, possibly due to greater osmotic resistance (Monteiro et al., 2011). Ejaculated and electroejaculated sperm seem to be less tolerant to high glycerol concentration. However, Anel et al. (2010) did not find differences in post-thawing sperm quality by using two glycerol 

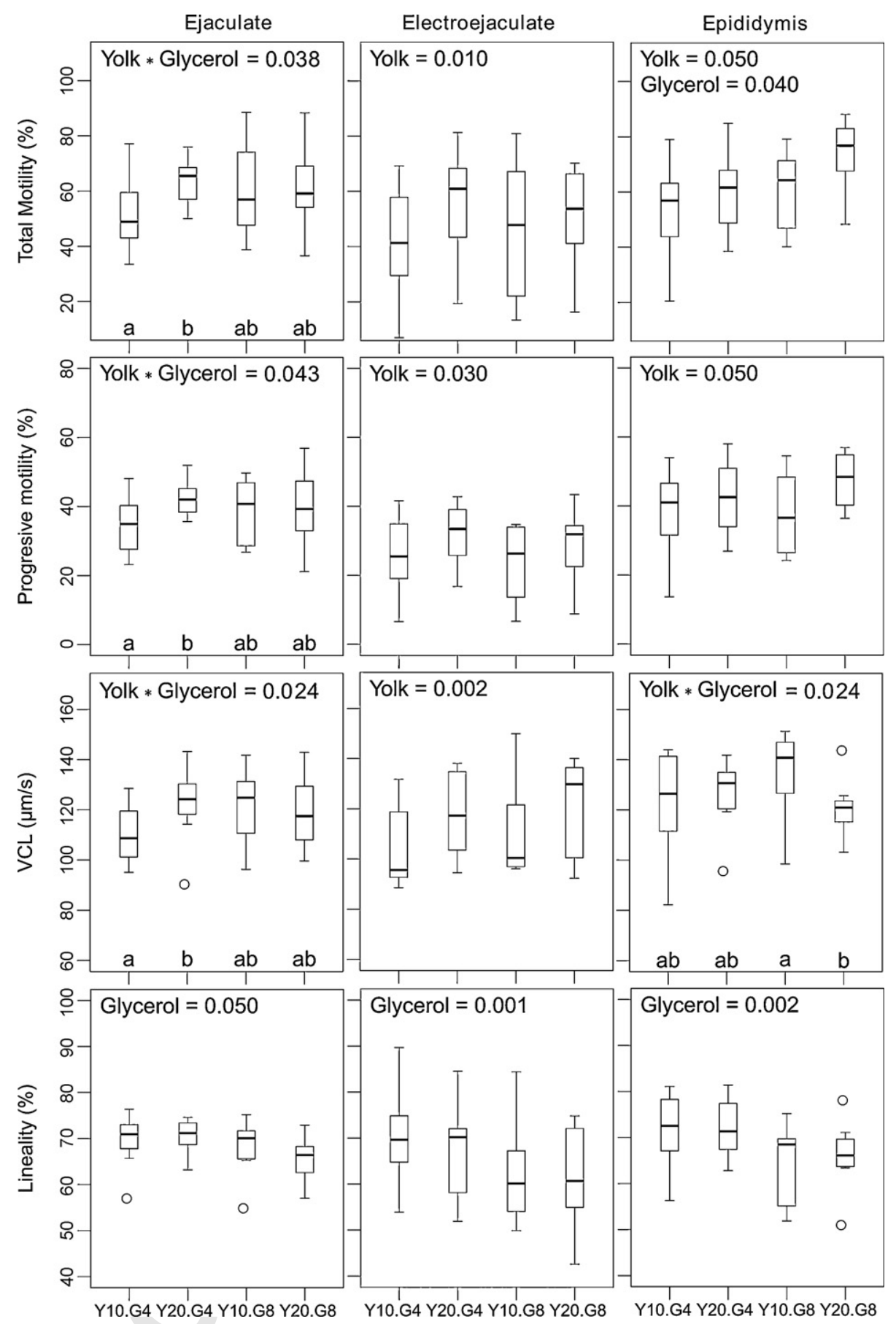

Fig. 3. Post-thawing motility and kinetic parameters (CASA). The boxplot shows the parameters of semen obtained from three sources (ejaculate, electroejaculate or cauda epididymis) evaluated in four extenders (two concentrations of egg yolk (Y10: 10\%, Y20: 20\%) and two concentrations of glycerol (G4: 4\%, G8: $8 \%$ ). Insets show whether the main effects (yolk or glycerol) or interactions (yolk $\times$ glycerol) were significant. Whenever a significant interaction was detected, a pairwise comparison was conducted of the 4 extenders (different letters indicate differences, $P<0.05$ ). The median is indicated by a horizontal line.

concentrations (4\% and $8 \%$ ) in electroejaculated samples recovered in brown bear, although de Paz et al. (2012) determined that $6 \%$ of glycerol could be more adequate than $4 \%$ or $8 \%$. It is possible that the susceptibility to different glycerol concentrations could vary among species, and that ram electroejaculated semen could be more sensitive to glycerol.

The vulnerability of electroejaculated spermatozoa to cryopreservation and glycerol concentrations could be due to differences in seminal plasma composition. The addition 


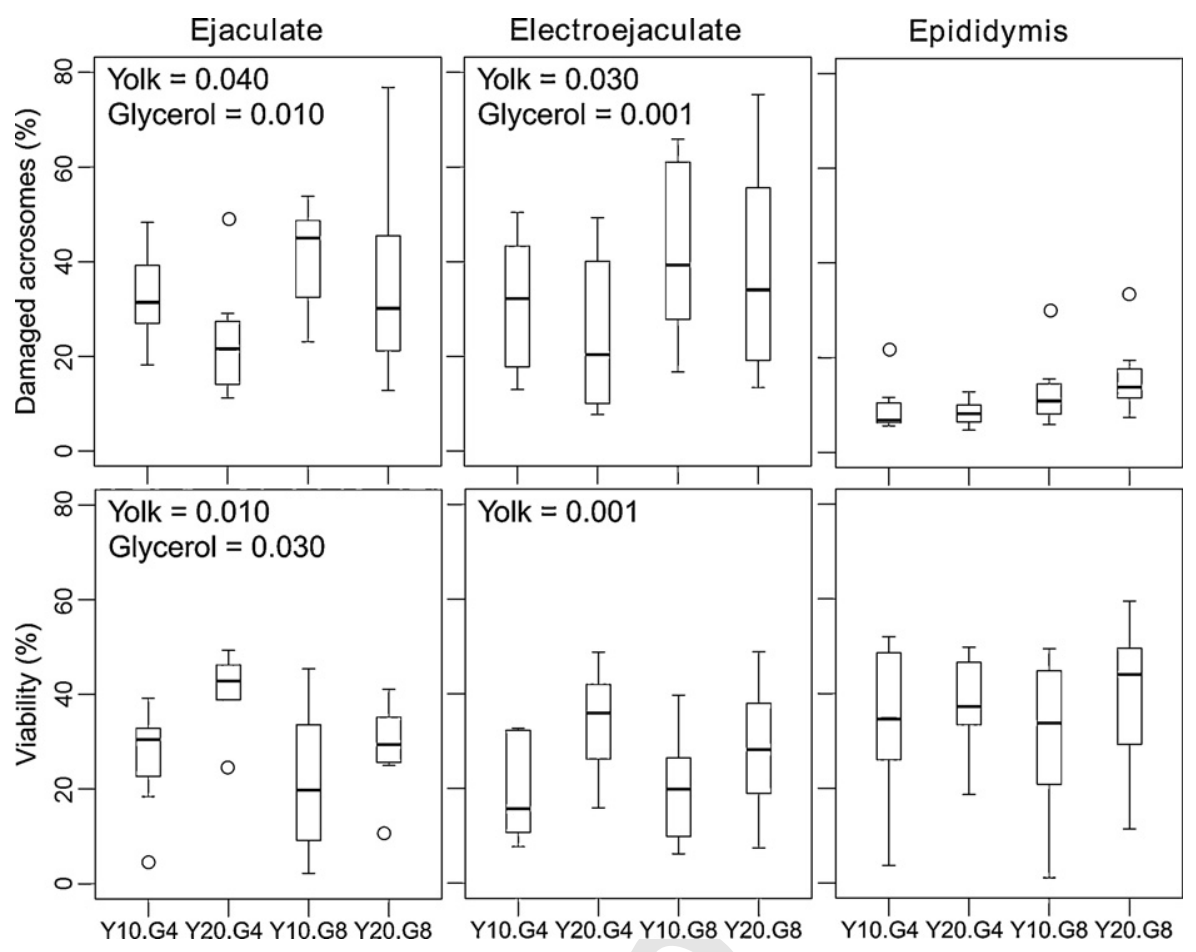

Fig. 4. Post-thawing viability parameters (flow cytometry). The boxplot shows the parameters of semen obtained from three sources (ejaculate, electroejaculate or cauda epididymis) evaluated in four extenders (two concentrations of egg yolk (Y10: 10\%, Y20: 20\%) and two concentrations of glycerol (G4: 4\%, G8: 8\%). Insets show whether the main effects (yolk or glycerol) or interactions (yolk $\times$ glycerol) were significant. Whenever a significant interaction was detected, a pairwise comparison was conducted of the four extenders (different letters indicate differences, $P<0.05$ ). The median is indicated by a horizontal line.

and removal of a variety of proteins during epididymal maturation and at ejaculation have important roles in the capacitation of sperm and fertilization (Yanagimachi, 1994). Barrios et al. (2000) suggested that the acquisition of seminal plasma proteins by adsorption to the sperm cell surface modifies the functional characteristics of damaged spermatozoa. Because electroejaculation varies from physiological ejaculation, the composition of seminal plasma could be different, inducing changes in spermatozoa that could make membranes less resilient (Marco-Jiménez et al., 2008). Electroejaculated samples were less suited to cryopreservation, possibly due to the variation in the composition and proportion of seminal plasma due to the stimulation of accessory glands, and this might have a negative effect on the freezability and fertility of these samples.

Cheng et al. (2004), working with electroejaculated sperm from Cervus nippon and Cervus unicolor, tested five different extenders with glycerol concentrations ranging from $5 \%$ to $8 \%$, and results suggested that the efficacy of each extender was due to the presence of specific components and the interactions, than to glycerol concentration alone. Several interactions were detected in the present study between glycerol and egg yolk, indicating that, for these parameters, the effect of one of these extender components depended on the concentration of the other. Nevertheless, in many cases only the main effects were significant, with no interaction.
Regarding egg yolk concentrations, results of the present study indicate that cryopreservation of ram spermatozoa obtained from the three sources provided for more desirable outcomes using an egg yolk concentration of $20 \%$. These results are similar to those obtained in other studies in ruminants. For example, FernándezSantos et al. (2006) found that the post-thawing quality of epididymal deer spermatozoa was greater using $20 \%$ egg yolk than $5 \%$ or $10 \%$. Anel et al. (2010) evaluated two egg yolk concentrations, $10 \%$ and $20 \%$, in electroejaculated sperm from brown bear, and it was observed that postthawing sperm motility, viability and acromosomal status was greater using an extender with an egg yolk concentration of $20 \%$. It has been suggested that the effects of egg yolk differ depending on the composition of the extender buffer. Thus, the greater egg yolk concentration in a kaffinose-based diluent resulted in a greater preservation of motility and membrane integrity during the cooling of spermatozoa in Cuvier's gazelle (Garde et al., 2008) or in red deer (Fernandez-Santos et al., 2007). Nevertheless, some authors have reported negative effects of high concentrations of egg yolk on the preservation of motility and acrosome integrity in Mohor gazelle spermatozoa cryopreserved in TEST-yolk diluent (Holt et al., 1996).

In conclusion, the present study is the first to simultaneously compare the cryopreservation of epididymal, ejaculated and electroejaculated spermatozoa from identical ram, and to assess the effect of different concentrations 
of glycerol and egg yolk. Epididymal spermatozoa seemed to be more resilient to cryopreservation, while ejaculated samples had greater quality post-thawing than electroejaculated samples. However, the greater in vitro quality of thawed epididymal samples does not imply a more desirable outcome of fertility in the field, and therefore it is assumed that other factors besides motility, viability and acrosome status, influence this result.

Regarding the concentration of egg yolk and glycerol, a $20 \%$ egg yolk concentration was more adequate for freezing ram spermatozoa regardless of its origin. It is recommended that freezing ejaculated or electroejaculated samples with $4 \%$ of glycerol is adequate, whereas $8 \%$ glycerol seems to be more adequate for freezing epididymal spermatozoa, possibly because of greater resistance to its toxic effects would allow these samples to benefit from its protective effects. These results could improve the cryopreservation of ram spermatozoa in different collection scenarios.

\section{Acknowledgements}

This research was supported in part by INIA (RZ201000005-00-00). Felipe Martínez-Pastor was supported by the Ramón y Cajal program (RYC-2008-02560, MICINN, Spain). The authors thank to María Mata-Campuzano, María Nicolas, and Manuel Alvarez-Rodríguez for their help in the acquisition and analysis of the samples.

\section{References}

Alvarez-Rodríguez, M., Alvarez, M., Gomes-Alves, S., Borragan, S. Martinez-Pastor, F., de Paz, P., Anel, L., 2011. Quality of frozen-thawed semen in brown bear is not affected by timing of glycerol addition. Theriogenology 75, 1561-1565.

Amirat, L., Tainturier, D., Jeanneau, L., Thorin, C., Gérard, O., Courtens, J.L., Anton, M., 2004. Bull semen in vitro fertility after cryopreservation using egg yolk LDL: a comparison with Optidyl, a commercial egg yolk extender. Theriogenology 61, 895-907.

Anel, L., de Paz, P., Alvarez, M., Chamorro, C.A., Boixo, J.C., Manso, A., González, M., Kaabi, M., Anel, E., 2003. Field and in vitro assay of three methods for freezing ram semen. Theriogenology 60, 1293-1308.

Anel, L., Álvarez, M., Martínez-Pastor, F., García-Macías, V., Anel, E., Paz, P., 2006. Improvement strategies in ovine artificial insemination. Reprod. pomest. Anim. 41 S2, 30-42.

Anel, L., Gomes-Alves, S., Alvarez, M., Borragan, S., Anel, E., Nicolas, M., Martinez-Pastor, F., de Paz, P., 2010. Effect of basic factors of extender composition on post-thawing quality of brown bear electroejaculated spermatozoa. Theriogenology 74, 643-651.

Barrios, B., Pérez-Pé, R., Gallego, M., Tato, A., Osada, J., Muiño-Blanco, T., Cebrián-Pérez, J.A., 2000. Seminal plasma proteins revert the coldshock damage on ram sperm membrane. Biol. Reprod. 63, 1531-1537.

Cancel, A., Lobdell, D., Mendola, P., Perreault, S.D., 2000. Objective evaluation of hyperactivated motility in rat spermatozoa using computer-assisted sperm analysis. Hum. Reprod. 15, 1322-1328.

Cheng, F.P., Wu, J.T., Chan, J.P.W., Wang, J.S., Fung, H.P., Colenbrander, B., Tung, K.C., 2004. The effect of different extenders on post-thaw sperm survival, acrosomal integrity and longevity in cryopreserved semen of Formosan Sika deer and Formosan Sambar deer. Theriogenology 61, 1605-1616.

Curry, M.R., Watson, P.F., 1994. Osmotic effects on ram and human sperm membranes in relation to thawing injury. Cryobiology 31, 39-46.

de Paz, P., Alvarez-Rodriguez, M., Nicolas, M., Alvarez, M., Chamorro, C., Borragán, S., Martinez-Pastor, F., Anel, L., 2012. Optimization of glycerol concentration and freezing rate in the cryopreservation of ejaculate from brown bear (Ursus arctos). Reprod. Domest. Anim. 47, 105-112.

Ehling, C., Rath, D., Struckmann, C., Frenzel, A., Schindler, L., Niemann, H., 2006. Utilization of frozen-thawed epididymal ram semen to preserve genetic diversity in Scrapie susceptible sheep breeds. Theriogenology 66, 2160-2164.

Fernández-Santos, M.R., Esteso, M.C., Montoro, V., Soler, A.J., Garde, J.J., 2006. Cryopreservation of Iberian red deer (Cervus elaphus hispanicus) epididymal spermatozoa: effects of egg yolk, glycerol and cooling rate. Theriogenology 66, 1931-1942.

Fernandez-Santos, M.R., Martinez-Pastor, F., Garcia-Macias, V., Esteso, M.C., Soler, A.J., de Paz, P., Anel, L., Garde, J.J., 2007. Extender osmolality and sugar supplementation exert a complex effect on the cryopreservation of Iberian red deer (Cervus elaphus hispanicus) epididymal spermatozoa. Theriogenology 67, 738-753.

Forouzanfar, M., Sharafi, M., Hosseini, S.M., Ostadhosseini, S., Hajian, M., Hosseini, L., Abedi, P., Nili, N., Rahmani, H.R., Nasr-Esfahani, M.H., 2010. In vitro comparison of egg yolk-based and soybean lecithinbased extenders for cryopreservation of ram semen. Theriogenology 73, 480-487.

García-Álvarez, O., Maroto-Morales, A., Martínez-Pastor, F., Garde, J.J., Ramón, M., Fernández-Santos, M.R., Esteso, M.C., Pérez-Guzmán, M.D., Soler, A.J., 2009. Sperm characteristics and in vitro fertilization ability of thawed spermatozoa from Black Manchega ram: electroejaculation and postmortem collection. Theriogenology 72, 160-168.

Garde, J.J., del Olmo, A., Soler, A.J., Espeso, G., Gomendio, M., Roldan, E.R.S., 2008. Effect of egg yolk, cryoprotectant, and various sugars on semen cryopreservation in endangered Cuvier's gazelle (Gazella cuvieri). Anim. Reprod. Sci. 108, 384-401.

Gillan, L., Skovgold, K., Watson, P.F., Evans, G., Maxwell, W.M., 1999. Fate and functional integrity of fresh and frozen-thawed ram spermatozoa following intrauterine insemination. Reprod. Fertil. Dev. 11, 309-315.

Hammerstedt, R.H., Parks, J.E., 1987. Changes in sperm surfaces associated with epididymal transit. J. Reprod. Fertil. Suppl. 34, 133-149.

Hishinuma, M., Suzuki, K., Sekine, J., 2003. Recovery and cryopreservation of sika deer (Cervus nippon) spermatozoa from epididymides stored at $4 \wedge \mathrm{C}$. Theriogenology $59,813-820$.

Holt, W.V., Abaigar, T., Jabbour, H.N., 1996. Oestrus synchronization, semen preservation and artificial insemination in the Mohor Gazelle (Gazella dama mhorr) for the establishment of a genome resource bank programme. Reprod. Fertil. Dev. 8, 1215-1222.

Holt, W.V., 2000. Basic aspects of frozen storage of semen. Anim. Reprod. Sci. 62, 3-22.

Hu, Y.H., Li, Q.W., Zan, L.S., Jiang, Z.L., An, J.H., Wang, L.Q., Jia, Y.H., 2010. The cryoprotective effect of low-density lipoproteins in extenders on bull spermatozoa following freezing-thawing. Anim. Reprod. Sci. 117, 11-17.

James, P.S., Wolfe, C.A., Ladha, S., Jones, R., 1999. Lipid diffusion in the plasma membrane of ram and boar spermatozoa during maturation in the epididymis measured by fluorescence recovery after photobleaching. Mol. Reprod. Dev. 52, 207-215.

Kaabi, M., Paz, P., Alvarez, M., Anel, E., Boixo, J.C., Rouissi, H., Herraez, P., Anel, L., 2003. Effect of epididymis handling conditions on the quality of ram spermatozoa recovered post-mortem. Theriogenology 60, 1249-1259.

Manjunath, P., Nauc, V., Bergeron, A., Ménard, M., 2002. Major proteins of bovine seminal plasma bind to the low-density lipoprotein fraction of hen's egg yolk. Biol. Reprod. 67, 1250-1258.

Marco-Jiménez, F., Puchades, S., Gadea, J., Vicente, J.S., Viudes-de-Castro, M.P., 2005. Effect of semen collection method on pre- and post-thaw Guirra ram spermatozoa. Theriogenology 64, 1756-1765.

Marco-Jiménez, F., Vicente, J.S., Viudes-de-Castro, M.P., 2008. Seminal plasma composition from ejaculates collected by artificial vagina and electroejaculation in Guirra ram. Reprod. Domest. Anim. 43, 403-408.

Martinez-Pastor, F., Martínez, F., García-Macías, V., Esteso, M.C., Anel, E., Fernández-Santos, M.R., Soler, A.J., de Paz, P., Garde, J., Anel, L., 2006. A pilot study on post-thawing quality of Iberian red deer spermatozoa (epididymal and electroejaculated) depending on glycerol concentration and extender osmolality. Theriogenology 66, 1165-1172.

Martinez-Pastor, F., Martínez, F., Alvarez, M., Maroto-Morales, A., GarcíaAlvarez, O., Soler, A.J., Garde, J.J., de Paz, P., Anel, L., 2009. Cryopreservation of Iberian red deer (Cervus elaphus hispanicus) spermatozoa obtained by electroejaculation. Theriogenology 71, 628-638.

Martins, C.F., Driessen, K., Costa, P.M., Carvalho-Neto, J.O., de Sousa, R.V., Rumpf, R., Dode, M.N., 2009. Recovery, cryopreservation and fertilization potential of bovine spermatozoa obtained from epididymides stored at $5 \wedge \mathrm{C}$ by different periods of time. Anim. Reprod. Sci. 116, 50-57.

Monteiro, G.A., Papa, F.O., Zahn, F.S., Dellaqua Jr., J.A., Melo, C.M., Maziero, R.R.D., Avanzi, B.R., Alvarenga, M.A., Guasti, P.N., 2011. Cryopreservation and fertility of ejaculated and epididymal stallion sperm. Anim. Reprod. Sci. 127, 197-201.
528

529

530

531

53

533

535

536

537

538
539

540

541

542

54

545

546

548

549

550

553

554

55

556

558

560

561
562

563

564

5

567

568

569

57

573
574 
Moussa, M., Marinet, V., Trimeche, A., Tainturier, D., Anton, M., 2002. Low density lipoproteins extracted from hen egg yolk by an easy method: cryoprotective effect on frozen-thawed bull semen. Theriogenology 57, 1695-1706.

Nel-Themaat, L., Harding, G.D., Chandler, J.E., Chenevert, J.F., Damiani, P. Fernandez, J.M., Humes, P.E., Pope, C.E., Godke, R.A., 2006. Quality and freezing qualities of first and second ejaculates collected from endangered Gulf Coast Native rams. Anim. Reprod. Sci. 95, 251-261.

R Development Core Team, 2010. R: A Language and Environment for Statistical Computing. R Foundation for Statistical Computing, Vienna, Austria, ISBN 3-900051-07-0, http://www.R-project.org/.Experientia.

Rath, D., Niemann, H., 1997. In vitro fertilization of porcine oocytes with fresh and frozen-thawed ejaculated or frozen-thawed epididymal semen obtained from identical boars. Theriogenology 47, 785-793.

Salamon, S., Maxwell, W.M., 2000. Storage of ram semen. Anim. Reprod. Sci. 62, 77-111.
Tamayo-Canul, J., Alvarez, M., López-Urueña, E., Nicolas, M., MartinezPastor, F., Anel, E., Anel, L., de Paz, P., 2011a. Undiluted or extended storage of ram epididymal spermatozoa as alternatives to refrigerating the whole epididymes. Anim. Reprod. Sci. 126, 76-82.

Tamayo-Canul, J., Álvarez, M., Mata-Campuzano, M., Álvarez-Rodríguez, M., de Paz, P., Anel, L., Martínez-Pastor, F., 2011b. Effect of storage method and extender osmolality in the quality of cryopreserved epididymal ram spermatozoa. Anim. Reprod. Sci. 129, 188-199.

Varisli, O., Uguz, C., Agca, C., Agca, Y., 2009. Motility and acrosomal integrity comparisons between electro-ejaculated and epididymal ram sperm after exposure to a range of anisosmotic solutions, cryoprotective agents and low temperatures. Anim. Reprod. Sci. 110, 256-268.

Yanagimachi, R., 1994. Fertility of mammalian spermatozoa: its development and relativity. Zygote 2, 371-372.

Yeung, C.H., Barfield, J.P., Cooper, T.G., 2006. Physiological volume regulation by spermatozoa. Mol. Cell. Endocrinol. 250, 98-105. 